\title{
Reporte de un caso clínico. Rehabilitación Fisioterapéutica Mediante Facilitación Neuromuscular Propioceptiva en paciente POST-COVID19
}

Report of a clinical case. Physiotherapeutic Rehabilitation Through Proprioceptive Neuromuscular Facilitation in POST-COVID19 patient

Relato de um caso clínico. Reabilitação Fisioterapêutica por Facilitação Neuromuscular Proprioceptiva em paciente PÓS-COVID19

Silvia del Pilar Vallejo Chinche

chivy_v@hotmail.es

https://orcid.org/0000-0002-8310-1071

Jorge Ricardo Rodríguez Espinosa

jrira2113@gmail.com

https://orcid.org/0000-0003-0287-9779

\author{
Sonia Alexandra Alvarez Carrión \\ sonnit.1204@hotmail.com \\ https://orcid.org/0000-0002-9439-2257
}

\author{
Guillermo Vinicio Granizo Mena \\ gvimo1387@gmail.com \\ https://orcid.org/0000-0002-6509-8542
}

Universidad Nacional de Chimborazo, Ecuador

Recibido 23 de junio 2021 / Arbitrado y aceptado 16 de septiembre 2021 / Publicado 30 de diciembre 2021

\begin{abstract}
RESUMEN
El virus por COVID-19 ha causado dificultades tanto físicas, psicológicas como respiratorias, entre los síntomas principales que presenta esta enfermedad resalta insuficiencia respiratoria a la que se suma la fragilidad física en respuesta a largos periodos de encamamiento en Unidad de Cuidados Intensivos. La investigación del caso clínico realizada a una paciente post COVID -19 quien tuvo una estancia prolongada de hospitalización, posteriormente tratada en su domicilio, donde la fisioterapia empleada se basó en la técnica de Facilitación Neuromuscular Propioceptiva combinada con ejercicios respiratorios que tienen como objetivo mejorar la funcionalidad del paciente post COVID-19. Se monitorizó los signos vitales al comienzo y final de la terapia. De igual manera se emplearon patrones bilaterales de F.N.P. en las extremidades superiores e inferiores, combinándose con los ejercicios respiratorios evidenciándose aumento de la capacidad respiratoria y mejorando el nivel de funcionalidad de la paciente. Se realizó una valoración mediante la escala de Borg para la percepción subjetiva de la dificultad respiratoria o del esfuerzo físico realizado.
\end{abstract}

Palabras clave: Facilitación; Neuromuscular; Propioceptiva; Virus; Terapia respiratoria

\begin{abstract}
The COVID-19 virus has caused both physical, psychological and respiratory difficulties, among the main symptoms that this disease presents is respiratory failure to which is added physical fragility in response to long periods of bedridden in the Intensive Care Unit. The clinical case investigation carried out on a post-COVID-19 patient who had a prolonged hospitalization stay, subsequently treated at home, where the physiotherapy used was based on the Proprioceptive Neuromuscular Facilitation technique combined with respiratory exercises that aim to improve the post-COVID-19 patient functionality. Vital signs were monitored at the beginning and end of therapy. Similarly, bilateral F.N.P. patterns were used. in the upper and lower extremities, combining with respiratory exercises, showing an increase in respiratory capacity and improving the level of functionality of the patient. An assessment was made using the Borg scale for the subjective perception of respiratory distress or physical exertion.
\end{abstract}

Key words: Facilitation; Neuromuscular; Proprioceptive; Virus; Respiratory therapy 


\section{RESUMO}

O vírus COVID-19 tem causado dificuldades físicas, psicológicas e respiratórias. Os principais sintomas desta doença incluem insuficiência respiratória e fragilidade física em resposta a longos períodos de descanso no leito na Unidade de Terapia Intensiva. O estudo de caso clínico foi realizado em um paciente pósCOVID-19 que teve uma estadia hospitalar prolongada, posteriormente tratado em casa, onde a fisioterapia utilizada foi baseada na técnica de Facilitação Neuromuscular Proprioceptiva combinada com exercícios respiratórios destinados a melhorar a funcionalidade do paciente pósCOVID-19. Os sinais vitais foram monitorados no início e no final da terapia. Da mesma forma, foram utilizados padrões de N.P.F. bilaterais nas extremidades superiores e inferiores, combinados com os exercícios respiratórios, mostrando um aumento na capacidade respiratória e melhorando o nível de funcionalidade do paciente. Foi feita uma avaliação utilizando a escala Borg para a percepção subjetiva da dificuldade respiratória ou do esforço físico realizado.

Palavras-chave: Facilitação; Neuromuscular; Proprioceptiva; Vírus; Terapia respiratória

\section{INTRODUCCIÓN}

En diciembre de 2019 se identificaron varias personas con sintomatología respiratoria, cuyo diagnóstico clínico fue de neumonía, su agente etiológico fue un $\beta$-coronavirus (un agente infeccioso que hasta ese entonces no se conocía que podía generar enfermedades respiratorias graves), todo ello ocurrió en 27 personas que estuvieron en contacto con un mercado mayorista de mariscos y animales en la ciudad de Wuhan, Hubei, China. El primer caso fue reportado el 08 de diciembre de 2019 y debido a que el número de personas enfermas alrededor del país se incrementó de forma exponencial, el 07 el Ministerio de Sanidad de China lo calificó como epidemia. Pocos días después de la aparición de la epidemia en
China, países como Tailandia, Corea del Sur, Italia, España, Portugal, Francia, e Inglaterra reportaron un considerable número de casos de personas con sintomatología respiratoria similar por lo que la Organización Mundial de la Salud (OMS) en marzo de 2020 declaró a la enfermedad causada por $\beta$-coronavirus como una nueva pandemia que hasta ese momento había generado una severa crisis económica, social y sanitaria; además denominó a la patología como COVID-19 desencadena por el SARS CoV $2(1,2)$.

El primer caso de COVID-19 reportado en el Ecuador correspondió a una ciudadana que arribó asintomática al país procedente de Europa (España) el 14 de febrero de ese año. Días posteriores a su llegada a la ciudad de Guayaquil fue desarrollando los síntomas, los mismos que consistieron en malestar general, fiebre y sintomatología respiratoria, razones por las que fue hospitalizada y diagnosticada de COVID -19, cuyo resultado fue positivo (3).

El nuevo coronavirus SARS CoV 2 está formado por ácido ribonucleico (ARN), forma parte de la familia Coronaviridae y de la orden Nidovirales. Sus principales particularidades consisten en el número, el tipo y tamaño de las proteínas estructurales presentes en la superficie del virus, estas proteínas favorecen su afinidad por las células humanas. Hasta el momento se han descrito seis especies del virus que provocan enfermedades leves en el humano como el resfriado (229E, OC43, NL63, HKU1). Dos especies pueden desencadenar 
patología respiratoria grave, así tenemos el síndrome respiratorio agudo severo (SARSCoV) y el síndrome respiratorio del Medio Oriente (MERS-CoV) que se caracterizan por la aparición de disnea (4).

Tanto el SARS en el año 2003 como el MERS-CoV en el año 2012 surgieron en China y Arabia Saudita respectivamente, en ambos casos las tasas de letalidad fueron menores en relación con el SARS CoV 2 (10\% para SARS y $37 \%$ para SARS CoV (5).

El SARS CoV 2 es un agente muy contagioso cuya transmisión ocurre rápidamente de persona a persona a través de secreciones respiratorias - microscópicos fómites (gotitas de hasta 5 micras), que las personas infectadas podrían expulsar al toser o estornudar. (6). Se conoce que este virus tiene alta afinidad para unirse con la enzima convertidora de angiotensina II (ACE II), la misma que es secretada por varios órganos de cuerpo humano, pero principalmente por los pulmones, razón por la cual el epitelio respiratorio es el más frecuentemente comprometido. (7).

La secuencia genética del SARS CoV 2 se asemeja en un $80 \%$ al SARSCoV, yaligual. Ambos expresan glucoproteínas transmembrana (proteínas en forma de pico) facilitándoles su adherencia a la célula objetivo. Estas proteínas en forma de pico presentes en la superficie del SARS CoV 2 se unen a los receptores de la enzima convertidora de angiotensina II (ACE II) localizadas en la superficie de las células humanas, inclusive con mayor facilidad que las del SARS CoV (7).
La ACE II es expresada principalmente por los neumocitos tipo II (células epiteliales del tracto respiratorio superior e inferior). La replicación viral de ARN ocurre dentro de estos neumocitos mediante la acción de la ARN pol (7).

El periodo de incubación del SARS CoV 2 se ha descrito que ocurre entre los primeros 5 y 7 días desde el momento del contagio, tiempo en el cual las personas infectadas desarrollan una amplia gama de sintomatología (fiebre, osteoartralgias, astenia, anosmia, ageusia, cefalea, disnea, neumonía, insuficiencia respiratoria, etc.). Otro grupo de personas infectadas pueden ser considerados casos son asintomáticos, es decir no mostrar síntomas, no obstante, pueden ser contagiosos o tienen cuadros leves con malestar general (8).

\section{Estructura del virus}

Este agente infeccioso a pesar de que microscópicamente es muy pequeño, comparado con otros virus, el SARS CoV 2 es grande y pesado cuyo diámetro oscila entre 60 a $140 \mathrm{~nm}$, su forma es esférica, tiene picos de aproximadamente 9 a $12 \mathrm{~nm}$ en su membrana en forma de corona de rey, particularidad ha hecho que sea denominado coronavirus. Como el resto de los coronavirus, SARS CoV 2 contiene cuatro proteínas estructurales principales, las cuales son: las proteínas espiga (S), membrana $(M)$, envoltura (E) y nucleocápside $(N)(8)$. 
La proteína $\mathrm{S}$ es una glucoproteína que media la unión al receptor del huésped. La proteína $M$ es la proteína estructural más abundante, lo que les permite unirse a la nucleocápside. La proteína $E$ también es una proteína transmembrana, se encuentra en pequeñas cantidades dentro del virión y facilita el ensamblaje y la liberación del virus, lo cual es importante para la patogénesis de la enfermedad. Finalmente, la proteína $\mathrm{N}$ es la única proteína presente en la nucleocápside que se compone de dos dominios separados capaces de unirse al ARN in vitro. Se cree que para la adecuada unión se requiere la contribución de ambos dominios y se ha sugerido que la fosforilación de la proteína $\mathrm{N}$ desencadena un cambio estructural que mejora la afinidad por el ARN viral en vez del ARN no viral. A su vez, se piensa que la proteína $\mathrm{N}$, en conjunto con la proteína $\mathrm{M}$, interacciona para empaquetar el genoma encapsulado en partículas virales (8).

Una quinta proteína estructural, la hemaglutinina-esterasa, presente en un subconjunto de $\beta$-coronavirus, permite la unión de las glucoproteínas de superficie. Se piensa que mejora la entrada hacia las células mediadas por la proteína $S$, y la propagación del virus a través de la mucosa (8).

\section{Variantes de coronavirus}

Hasta el momento las variantes más representativas del virus son alfa, beta, gamma, delta, omicron, IHU y en los últimos días se ha dado a conocer una nueva que de acuerdo a reportes de científicos europeos es una combinación de delta y omicron, bautizada como deltacron; siendo los cinco primeros quienes infectan a los humanos, provocando enfermedades que van desde un resfrío leve hasta infecciones severas (9).

\section{DESCRIPCIÓN DEL CASO CLÍNICO}

Paciente de sexo femenino adulta joven de 50 años, de nacionalidad ecuatoriana oriunda del cantón Riobamba, de estado civil casada, progenitora de 2 hijos, de ocupación comerciante, refiere haberse contagiado en su lugar de trabajo que consiste en atención al cliente directo en su negocio, posteriormente presenta sintomatología de resfrío por lo que asiste a consulta con un médico en medicina general el cual le prescribe examen de laboratorio PCR para descartar posible COVID-19, los cuales resultan negativo. El médico tratante revisa los resultados y diagnostica un resfriado común por lo que prescribe medicación de acuerdo al cuadro clínico, con el pasar de los días la paciente empeora sus síntomas, y recurre nuevamente al médico tratante quien le solicita una TAC simple de pulmones donde se reporta neumonía, el galeno receta Dióxido de cloro y antibiótico para neumonía bacteriana, luego de cuatro días con el tratamiento no se evidencia mejoría por lo que requiere hospitalización por baja saturación y dificultad para respirar, 
permanece 30 días bajo ventilación mecánica invasiva en la $\mathrm{UCl}$ por cuadro de insuficiencia respiratoria aguda por neumonía atípica por SARS COV2 confirmada el 03-09-2020.

El estudio tomográfico simple muestra múltiples áreas de infiltrado alveolar en vidrio esmerilado, de ubicación periférica subpleural y central en lóbulos superiores asociándose a áreas de engrosamiento septal postrobasal bilateral a predominio izquierdo, hallazgos en relación con neumonía multifocal atípica característico de COVID 19. CORADS 5 (Figura 1).

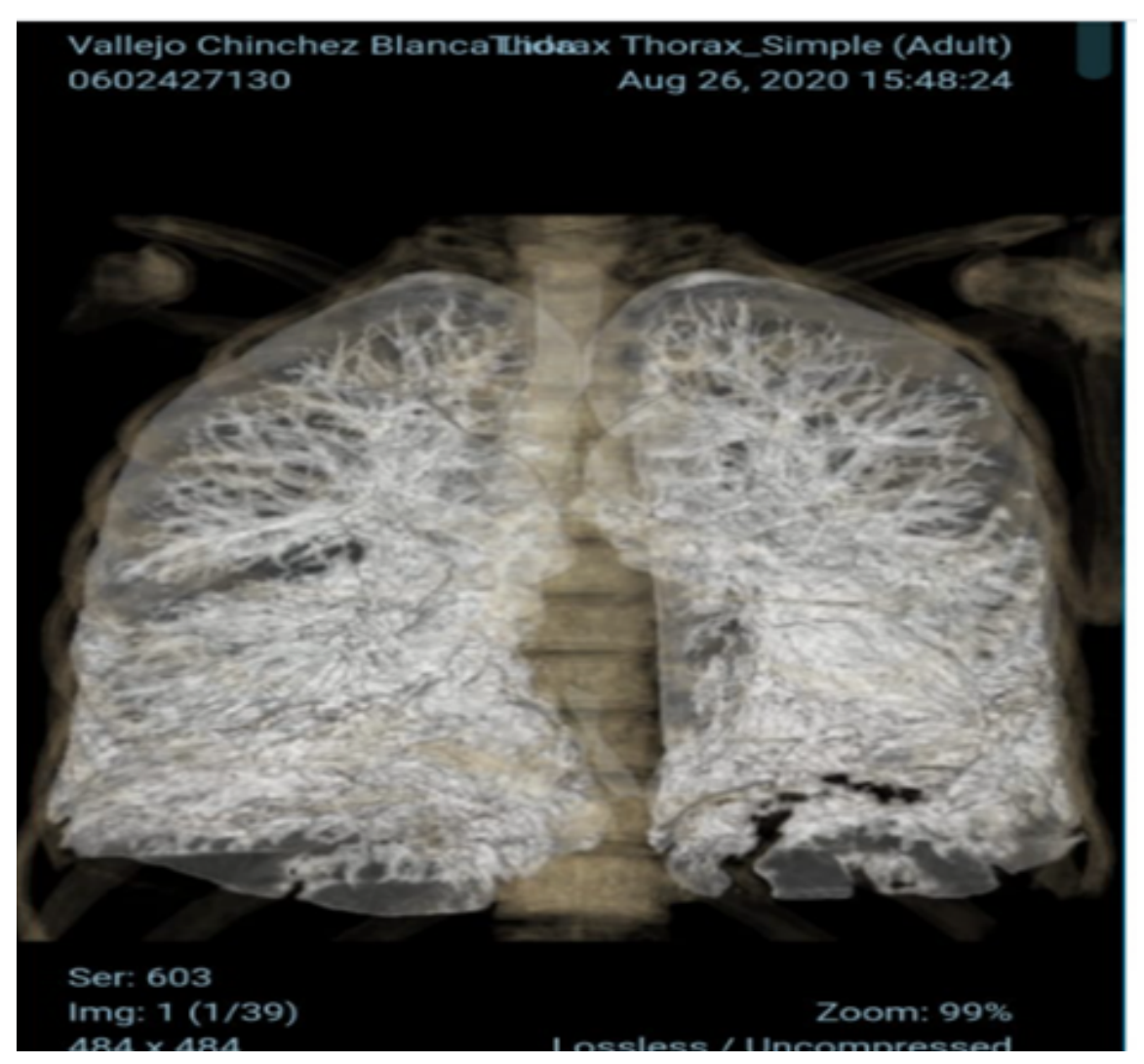

Figura 1. Estudio tomográfico simple.

Estudio tomográfico simple que muestra múltiples áreas de infiltrado alveolar en vidrio es esmerilado, hallazgos en relación con neumonía multifocal atípica característico de COVID 19. CORADS.

El 5-10-2020 le trasfieren de la unidad de cuidados intensivos al área de hospitalización al presentar mejoría, no presenta signos de daños neurológico, en condiciones cardiacas estables, donde permanece por 2 días y se considera el alta hospitalaria con oxígeno domiciliario y prescripción de terapia física y respiratoria. 
Al examen físico en pulmones presenta murmullo vesicular disminuido, se ausculta estertores crepitantes a nivel de ambos campos pulmonares. A nivel abdominal manifiesta dolor a la palpación, dolor en extremidades superiores e inferiores y el tono muscular disminuido.

Además, presenta dificultad para caminar, disminución de la masa muscular, disnea: paciente presenta dificultad para respirar al realizar ejercicios, dolor en extremidades: paciente refiere dolor al realizar actividad física, disminución de la capacidad respiratoria. Como diagnóstico fisioterapéutico emitido: presenta reducción de la fuerza, limitados rangos articulares con predominio en articulaciones del tobillo y cadera, presenta dolor a nivel de varios segmentos corporales con énfasis a nivel lumbar, presenta marcha antiálgica.

Con respecto a la percepción subjetiva de la dificultad respiratoria o del esfuerzo físico realizado, se valoró mediante la escala de Borg; Al finalizar el tratamiento fisioterapéutico la paciente refirió menor agotamiento físico durante las sesiones, mejorando la funcionalidad en sus actividades de la vida diaria (Tabla 1).

Tabla 1. Evolución de los signos vitales.

\begin{tabular}{cccccc}
\hline \multirow{2}{*}{ SIGNOS VITALES } & \multirow{2}{*}{ PRIMERA SESIÓN } & SEGUNDA SESIÓN & TERCERA SESIÓN & CUARTA SESIÓN & QUINTA SESIÓN \\
\hline SATURACIÓN & $87 \%-89 \%$ & $90 \%-95 \%$ & $90 \%-90 \%$ & $95 \%-97 \%$ & $96 \%-96 \%$ \\
PULSO & $73-80$ & $70-90$ & $75-90$ & $65-90$ & $68-75$ \\
PRESIÓN & $131-92$ & $124-75$ & $119-80$ & $124-84$ & $121-75$ \\
ARTERIAL & $135-95$ & $130-82$ & $127-84$ & $129-86$ & $128-84$ \\
\hline
\end{tabular}

Durante dicho tratamiento de técnicas de FNP empleado, se evidenció las variaciones de la presión arterial y pulso, a la cuarta sesión hubo un aumento de pulso más que en las otras sesiones empleadas, mientras que la presión arterial en la primera sesión fue el valor más alto reportado durante el tratamiento; al igual que la saturación de oxígeno se observa un aumento durante la ejecución de la técnica. Se observa que la paciente presenta una adaptación al esfuerzo realizado (Figura 2). 
ESCALA DE ESFUERZO DE BORNG

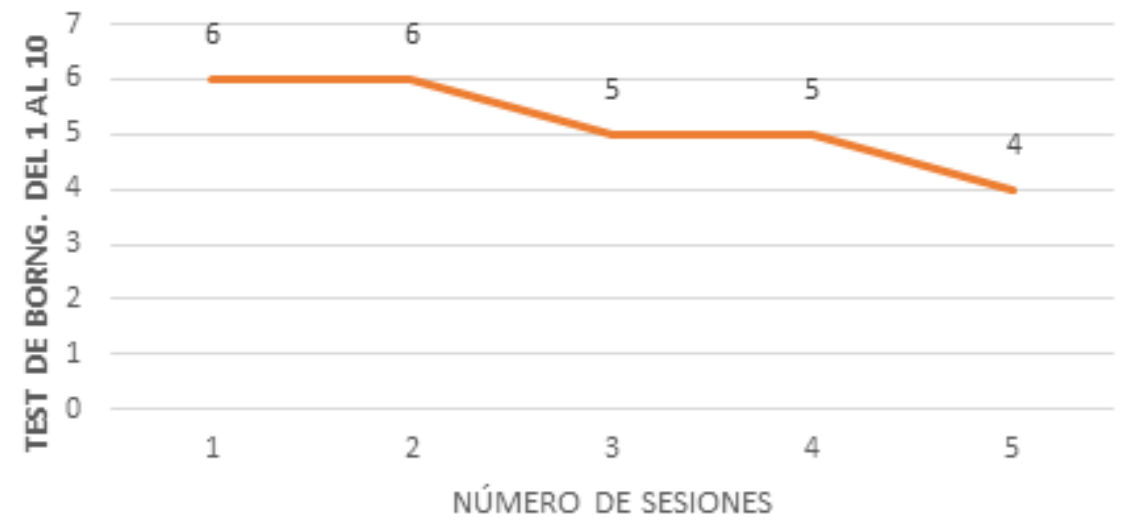

Figura 2. Escala Esfuerzo Físico de Borg.

\section{DISCUSIÓN}

Durante el tratamiento del caso nos permitió describir el trabajo con FNP sobre pacientes post COVD-19, para mejorar la mecánica respiratoria y por ende optimizar la ventilación; se tiene evidencia que al combinar ejercicios dinámicos de los miembros superiores junto a ejercicios respiratorios dan como resultado una mejor función pulmonar (10). En este tipo de casos se recalca la necesidad de un abordaje integral tanto físico como respiratorio en pacientes asociados a la infección post COVID - 19, teniendo en cuenta el cuadro clínico que presenta cada individuo infectado por este virus, para tener un mejor enfoque en cuanto a la evolución del paciente en su rehabilitación a corto y largo plazo (11).

\section{Al examen físico}

Pulmones: Murmullo vesicular disminuido, se ausculta estertores crepitantes a nivel de ambos campos pulmonares. Abdomen: doloroso a la palpación, Extremidades: dolor en extremidades superiores e inferiores, Tono muscular: disminuido.

\section{Evolución}

En cuanto a la evolución; la paciente al inicio del tratamiento establecido, mostró dificultad al realizar los patrones de la FNP a causa de no poder coordinar la respiración con las diagonales de ejercicios, desencadenando alza en la presión y disminución en la saturación de oxígeno, posteriormente en las siguientes sesiones se observa una mejor coordinación de las diagonales de la FNP en combinación con la respiración manteniéndose estable los signos vitales.

Durante el tratamiento fisioterapéutico mediante técnicas de FNP empleado se evidenció las variaciones de la presión arterial y pulso, a la cuarta sesión hubo un aumento de pulso más que en las otras sesiones empleadas, 
mientras que la presión arterial en la primera sesión fue el valor más alto reportado durante el tratamiento, al igual que la saturación de oxígeno se observa un aumento durante la ejecución del tratamiento.

En la ejecución del tratamiento se observa que se presenta una mejoría del esfuerzo con que la paciente ejecuta los patrones de ejercicios establecidos, de la primera sesión de más pasada a la quinta sesión mostrando en la categoría en algo pasada.

\section{CONCLUSIONES}

En conclusión, este caso reporta un resultado favorable a corto plazo al aplicar la técnica de FNP en los patrones establecidos en miembros superiores e inferiores que combinada con un buen trabajo de la respiración (inspiración y espiración) permitió a la paciente mejorar la funcionalidad y posterior realización de sus actividades diarias post COVID -19. Es importante resaltar que se debe seguir con el tratamiento a largo plazo y realizar un continuo seguimiento en dichos pacientes para tener un mejor contexto del tipo de rehabilitación a ser aplicado.

\section{Agradecimientos}

Agradecemos la cooperación y atención adecuada del Centro de Rehabilitación Integral "Physical Med" de Riobamba, igualmente a la paciente que estuvo presta a colaborar en el cumplimiento de este estudio, así como a los médicos tratantes y fisioterapeutas colaboradores que nos guiaron en la puesta en marcha de esta investigación.

\section{REFERENCIAS BIBLIOGRÁFICAS}

1. Rai P. Detection technologies and recent developments in the diagnosis.pdf. 2021;44155.

2. Ministerio de Sanidad. Actualización $\mathrm{n}^{\circ}$ 13. Neumonía por nuevo coronavirus (2019nCoV) en Wuhan, provincia de Hubei, (China). Madrid: Ministerio de Sanidad; 2020. (Citado el 15 de abril del 2020). Disponible en: https://www.mscbs.gob. es/profesionales/ saludPublica/ccayes/ alertasActual/nCovChina/documentos/ Actualizacion_13_2019nCoV_China.pdf

3. Caicedo H, Abad V. Desigualdades, impactos y desafios, la pandemia en Ecuador. Obs Soc en Ecuador y FES-Ildis [Internet]. 2020;53(9):1-27. Available from: www.covid19ecuador.org

4. S. Belouzard, V. Chu, G.R. Whittaker Activation of the SARS coronavirus spike protein via sequential proteolytic cleavage at two distinct sitesProc Natl Acad Sci U S A, 106 (2009), pp. 5871-5876

5. Adhikari SP, Meng S, Wu YJ, Mao YP, Ye RX, Wang Q-Z, et al. Epidemiology, causes, clinical manifestation and diagnosis, prevention and control of coronavirus disease (COVID-19) during the early outbreak period: a scoping review. Infect Dis Poverty. 2020;9(1):29. Available in: https://doi.org/10.1186/s40249020- 00646-x

6. Hung LS. The SARS epidemic in Hong Kong: what lessons have we learned? J R Soc Med. 2003; 96(8):374-8. doi: 10.1258/jrsm.96.8.374

7. Accinelli, Roberto Alfonso et al. COVID-19: la pandemia por el nuevo virus SARS-CoV-2. Revista Peruana de Medicina Experimental y Salud Pública [online]. 2020, v. 37, n. 2 [Accedido 12 Enero 2022], pp. 302-311. Disponible en: <https://doi.org/10.17843/ rpmesp.2020.372.5411>. Epub 28 Ago 2020. ISSN 1726-4642. https://doi.org/10.17843/ rpmesp.2020.372.5411

8 Alvarado Al, Bandera AJ, Carreto BLE, et al. Etiología y fisiopatología del SARS-CoV-2. Rev 
Latin Infect Pediatr. 2020;33(Suppl: 1):59. doi:10.35366/96667.

9. Maguiña Vargas Ciro, Gastelo Acosta Rosy, Tequen Bernilla Arly. El nuevo Coronavirus y la pandemia del Covid-19. Rev Med Hered [Internet]. 2020 Abr [citado 2022 Ene 13];31(2):125-131. Disponible en: http://www.scielo.org.pe/ scielo.php?script=sci_arttext\&pid=S1018130X2020000200125\&lng=es. http://dx.doi. org/10.20453/rmh.v31i2.3776.

10 Han JW, Kim YM. Effect of breathing exercises combined with dynamic upper extremity exercises on the pulmonary function of young adults. J Back Musculoskelet Rehabil. 2018;31(2):405-9.

\section{ACERCA DE LOS AUTORES}

Silvia del Pilar Vallejo Chinche. Licenciada en Ciencias de la Salud en Fisioterapia Deportiva. Magister en Fisioterapia y Rehabilitación mención Neuromusculoesquelético. Fisioterapeuta del Centro de Rehabilitación Integral PHYSICAL-MED de la ciudad de Riobamba. Universidad Nacional de Chimborazo, Ecuador.

Sonia Alexandra Alvarez Carrión. Licenciada en Ciencias de la Salud en Fisioterapia Deportiva. Magister en Fisioterapia y Rehabilitación mención Neuromusculoesquelético. Magister en Gerencia de los Servicio de la Salud. Gerente Fisioterapeuta del Centro de Rehabilitación Integral PHYSICAL-MED de la ciudad de Riobamba. Docente de la carrera de Terapia Física y Deportiva / Fisioterapia de la Universidad Nacional de Chimborazo, Ecuador.

Jorge Ricardo Rodríguez Espinosa. Doctor en Medicina. Especialista en Medicina General Integral. Máster en Longevidad Satisfactoria. Docente investigador de la carrera de Terapia Física y Deportiva / Fisioterapia de la Universidad Nacional de Chimborazo, Ecuador.

Guillermo Vinicio Granizo Mena. Médico General. Magíster en Biología de las Enfermedades Infecciosas. Máster universitario en Sistemas Integrados de Gestión de la Prevención de Riesgos Laborales. Docente de la carrera de Terapia Física y Deportiva / Fisioterapia de la Universidad Nacional de Chimborazo, Ecuador.
11. Özkeskin M, Elibol N, Bakırhan S. Risk of COVID-19 disease in the elderly population and physiotherapy. Physiotherapy. 2020;108:76-7.

Conflicto de intereses: Ninguno declarado por los autores.

Financiación: Ninguna declarada por los autores.

Agradecimiento: Ninguno manifestado por los autores 